\title{
Effects of pre- and post-transplant inoculation with com- mercial arbuscular mycorrhizal (AM) fungi on pelargonium (Pelargonium hortorum) and its microorganism community
}

\author{
Gergely Csima, Ildikó Hernádi and Katalin Posta \\ Microbiology and Environmental Toxicology Group, Plant Protection Institute, \\ Szent István University, 2100 Gödöllő, Hungary \\ e-mail: posta.katalin@mkk.szie.hu
}

\begin{abstract}
Rooted cuttings of geranium (Pelargonium hortorum var. Greco) were grown with and without a slow release fertilizer (OSM+, OSM-) and inoculated or not with a commercial inoculum containing arbuscular mycorrhizal fungi (AM1+, AM1-). After six weeks plants were transplanted into larger containers and one-half of the plants were inoculated with $\mathrm{AM}(\mathrm{AM} 2+)$. After six weeks of growth, inoculation increased pelargonium growth along with nitrogen $(\mathrm{N})$, phosphorous $(\mathrm{P})$ and potassium $(\mathrm{K})$ concentrations in shoot. The addition of AM during transplantation caused a slight decrease in shoot growth in OSM- treatment and enhanced $\mathrm{N}$ concentration. It was found that the earlier the mycorrhizal symbiosis was established the greater its benefits were. Colony forming units of total fungi and bacteria in the rhizosphere were not influenced by AM; although restriction fragment length polymorphism (RFLP) profiles of DNA isolated from bacteria living in rhizosphere showed a more diverse community in AM-inoculated than non-inoculated plants at low nutrient supply. Our results suggest that mycorrhizal inoculation not only has an effect on plant growth and uptake of elements but it also influences directly or indirectly the bacterial community of the rhizosphere, which in turn might also play a role in the growth and nutrient uptake of the host plant.
\end{abstract}

Key words: pelargonium, arbuscular mycorrhizal fungi, beneficial microorganisms

\section{Introduction}

A wide variety of growing substrates is used in the commercial production of ornamental plants and many of these substrates contain a low count of soil organisms (e.g. bacteria and fungi). However, sterile or aseptic conditions not only eliminate pathogenic but also beneficial microorganisms which could play a positive role in the uptake of minerals and plant protection.

Plants in most of the major plant families form symbiotic associations between their roots and mycorrhizal fungi in nature. One type of mycorrhizal association, the arbuscular mycorrhizal (AM) symbiosis, can contribute significantly to plant nutrition by promoting the uptake of phosphorus, nitrogen, zinc, copper and potassium (George 2000) resulting in improved plant growth and health. Colonization by AM may also improve rooting and plant establishment and enhance plant tolerance to biotic and abiotic stress (Schützendübel and Polle 2002).

Early evidence of the positive influence of the AM symbiosis on horticultural production was provided by Menge et al. (1977). Inoculation of horticultural plants with AM can (i) improve rooting and plant establishment; (ii) increase uptake of some ions and influence nutrient cycling; (iii) enhance plant tolerance to (biotic and abiotic) stress; (iv) improve the quality of soil structure; (v) promote earlier flowering and fruiting; and (vi) increase crop uniformity. The effects of AM on the growth and development of horticultural crop plants have been described in many research papers (Azcón-Aguilar and Barea 1997, Lovato et al. 


\section{AGRICULTURAL AND FOOD SCIENCE}

G. Csima et al. (2012) 21: 52-61

1995) but research attention has mainly been focused on fruit crops, rather than on ornamental plants such as pelargonium (Nowak 2004, 2007).

Pelargonium production from root cuttings uses either organic nutrients in the form of compost or soilless growing substrates (mostly peat) amended with inorganic fertilizers. In both cases growers need to balance the high nutrient demand of young plants with the reduced availability and high costs of peat substrates. More information on the applications of AMF in horticulture would be desirable because high levels of phosphorus commonly used in commercial growing substrates often limits mycorrhizal formation (Nagahashi et al. 1995). Mycorrhizal inoculum is commonly produced by means of 'trap' culture which, besides being a sterilized substrate, contains a community of microorganisms living together with mycorrhizal fungi. There are only very few data concerning the role of microorganisms in association with mycorrhizal fungi in how mycorrhizae affect plant growth. Understanding the changes in the population of microorganism due to mycorrhizal inoculation is an important prerequisite of effective management in sustainable agricultural systems.

Our aim was to better understand the influence of mycorrhizal inoculums Symbivit (Symbio-m, CZ) on the growth of pelargonium at slow release fertilizer supply and improve our knowledge on how AM fungi influences the community of microorganisms living in the rhizosphere.

\section{Materials and methods}

\section{Experiment 1. Inoculation with mycorrhizal fungi before transplantation (pre-}

Rooted cuttings of geranium (Pelargonium hortorum var. Greco) were planted in containers filled with $500 \mathrm{~cm}^{3}$ of substrate with the following characteristics: $\mathrm{pH}\left(\mathrm{H}_{2} \mathrm{O}\right): 6.47, \mathrm{NO}_{3}-\mathrm{N}: 71.5 \mathrm{mg} \mathrm{kg}^{-1}, \mathrm{P}_{2} \mathrm{O}_{5}: 230 \mathrm{mg}$ $\mathrm{kg}^{-1}, \mathrm{~K}_{2} \mathrm{O}: 192 \mathrm{mg} \mathrm{kg}^{-1}$, organic matter: 5.37\%. Phosphorus, potassium and nitrogen concentrations were determined according to Egner et al. (1960) using ammonium lactate-acetic acid and $\mathrm{CaCl}_{2}$ extraction, respectively.

Substrate was enriched in one-half of the containers by a slow release fertilizer (Osmocote) at a reduced rate of $2 \mathrm{gl}^{-1}(15 \mathrm{~N}+9 \mathrm{P}+12 \mathrm{~K}+2.5 \mathrm{MgO}+$ microelements $)$. A commercial mycorrhizal inoculums, Symbivit (mixture of Glomus intraradices, G. claroideum, G. microaggregatum, G. mosseae and G. etunicatum) produced by Symbio-m (CZ) was added at an amount of $30 \mathrm{~g} \mathrm{l}^{-1}$ to half of the fertilizer enriched and nonenriched containers. The four treatments (1: AM1+OSM+; 2: AM1+OSM-; 3: AM1-OSM+; 4: AM1-OSM-) of 100 plants with 25 replications per treatments were arranged in a completely randomized design. Drip irrigation was used to maintain substrate moisture content close to field capacity values $(20 \% \mathrm{w} / \mathrm{w})$ during the growth period. The experiment was carried out from 17 February to 4 April in 2009 under greenhouse

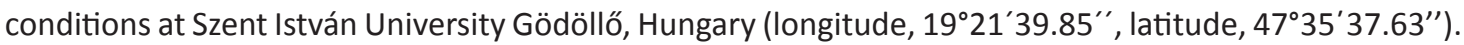
Average air temperature in the greenhouse during the study period was $19.5^{\circ} \mathrm{C}$ (minimum of $14{ }^{\circ} \mathrm{C}$ and maximum of $25^{\circ} \mathrm{C}$ ). Plants were destructively harvested at the end of the experiment ( 6 weeks), separated into shoots and roots, dried at $60^{\circ} \mathrm{C}$ for $72 \mathrm{~h}$ and weighed. In addition, the nutrient content of the leaves $(\mathrm{P}, \mathrm{K})$ was measured after the wet digestion of plant samples with $\mathrm{HNO}_{3}+\mathrm{H}_{2} \mathrm{O}_{2}$. The quantity of elements was measured by means of an inductively coupled plasma atomic emission spectrometry (ICP-AES, type: FY-238). The amount of nitrogen was estimated by a modified Kjeldahl method (Benton 1991) after wet digestion with cc. $\mathrm{H}_{2} \mathrm{SO}_{4}+\mathrm{H}_{2} \mathrm{O}_{2}$. 


\section{AGRICULTURAL AND FOOD SCIENCE}

G. Csima et al. (2012) 21: 52-61

A representative subsample of the root was cut to $10 \mathrm{~mm}$ pieces and five randomly selected pieces from each sample were subjected to Trypan Blue staining (Phillips and Hayman 1970). Internal fungal structures (hypae, arbuscules) were examined under a stereomicroscope at $\times 100$ magnification and the percentage of root length colonization was calculated using the gridline intersect method (Giovannetti and Mosse 1980).

\section{Determination of rhizosphere microorganisms}

Aliquots $(5 \mathrm{~g})$ of rhizosphere soil originating from each treatment of experiment 1 . were transferred to sterile bottle containing $25 \mathrm{~cm}^{3} 0.9 \% \mathrm{NaCl}$ solution and shaken for 10 minutes on a mechanical shaker. Of this soil suspension, a tenfold dilution series was prepared and $0.1 \mathrm{~cm}^{3}$ was plated out on different sterilized $\left(121^{\circ} \mathrm{C}\right.$, $20 \mathrm{~min}$ ) culture media. The number of colony forming units (CFU) per gram of rhizosphere soil was estimated for total fungi and total aerobic bacteria as well as for Pseudomonas sp. using Czapek Dox Agar (Duchefa Biochemia BV, NL), BD Difco ${ }^{\mathrm{TM}}$ Nutrient Agar and Pseudomonas Isolation Agar (Fluka, Sigma-Aldrich Chemie $\mathrm{GmbH}, \mathrm{CH}$ ), respectively. The plates were incubated at $28^{\circ} \mathrm{C}$ for $48 \mathrm{~h}$ (total aerobic bacteria, Pseudomonas sp.) or for 5 days (total fungi). All tests were performed in five replicates.

\section{Experiment 2. Inoculation with mycorrhizal fungi during transplantation (post-in- oculation)}

The remaining plants from experiment 1., together with the original substrate were transplanted on 4 April into $4000 \mathrm{~cm}^{3}$ containers (two plants in one container) filled with the same substrate used in experiment 1. without additional OSM fertilization. The substrate in half of the containers of the original four OSM $x$ AM treatments from experiment 1., was amended with Symbivit (15 g container $\left.{ }^{-1}\right)$. The eight treatments (80 plants, 10 replications per treatment) were cultivated in a greenhouse for six additional weeks and irrigated as in experiment 1.

Plants were harvested at the end of the experiment and the dry weight of roots and shoots, the nutrient content of the leaves were determined as in experiment 1 . Also, mycorrhiza frequency was measured as described above.

\section{Molecular analysis}

Roots originated from experiment 1 . and experiment 2. were shaken vigorously to separate the rhizosphere soil from the roots and rhizosphere soil were collected, homogenized separately using a sterilized pestle. From each sample, $500 \mathrm{mg}$ of soil was used for DNA extraction using a FastDNA SPIN kit for Soil (Q-Biogene Inc., Irvine, CA). The bacterial 16S rRNA gene was amplified using the following concentrations of PCR reaction $(20 \mu \mathrm{l}): 2 \mu \mathrm{l}$ 10×PCR buffer (Fermentas, Vilnius, Lithuania), $1.5 \mu \mathrm{l} 25 \mathrm{mM} \mathrm{MgCl}_{2}, 2 \mu \mathrm{l}$ dNTP mix, $1.0 \mu \mathrm{l}$ of each primer (40 mM) 27f (5'- AGA GTT TGATCC TGG CTC AG-3') and 534r (5'-ATT ACC GCG GCT GCT GG-3') (Muyzer et al. 1993), $1 \mu \mathrm{l}$ of template DNA, $0.2 \mu \mathrm{l}(5 \mathrm{U})$ Taq polymerase (Fermentas, Vilnius, Lithuania), and $11.3 \mu \mathrm{lmilliQ}$ water. The thermocycler program started with denaturation at $95^{\circ} \mathrm{C}$ for $5 \mathrm{~min}$, followed by 25 cycles of $94{ }^{\circ} \mathrm{C}$ for $30 \mathrm{~s}, 56{ }^{\circ} \mathrm{C}$ for $45 \mathrm{~s}$ and $72{ }^{\circ} \mathrm{C}$ for $60 \mathrm{~s}$, and ended by a final extension at $72{ }^{\circ} \mathrm{C}$ for 7 min. Amplification products were separated by electrophoresis in $1.5 \% \mathrm{~W} \mathrm{~V}^{-1}$ agarose gels and stained with ethidium bromide. Cleaned PCR products were digested overnight at $37^{\circ} \mathrm{C}$ using the restriction endonucleases Hin6I (synonym name HinP1I), BsuRI (synonym name HaellI) (Promega, Madison, WI, USA). The RFLP profiles were analyzed with Agilent 2100 Bioanalyzer according to DNA 12000 Kit (Agilent Technologies, Waldbronn, Germany) manufacturer's protocol. 


\section{AGRICULTURAL AND FOOD SCIENCE}

G. Csima et al. (2012) 21: 52-61

\section{Statistics}

The effects of mycorrhizal inoculation and Osmocote addition on dry matter production and nutrient concentrations were tested in experiment 1 . with two-factorial analysis of variance. Mean separation was carried out with the Tukey test $(p<0.05)$ in experiment 2. Data were analyzed using Statistica 6.1 (StatSoft, Tulsa, OK, USA) software.

\section{Results \\ Experiment 1. Inoculation with mycorrhizal fungi before transplantation (pre-}

Lower than $10 \%$ of root colonization was measured during the first six weeks of growth in both OSM-and $\mathrm{OSM}+$ treatments and there was no significant difference between the two treatments (Table 1).

Table 1. Effects of mycorrhizal inoculation and nutrient supply on growth, element concentrations measured in shoots and root colonization after six weeks of growth.

\begin{tabular}{|c|c|c|c|c|c|c|}
\hline \multirow{2}{*}{ Treatments } & \multicolumn{2}{|c|}{ Dry weight $\left[\mathrm{g} \mathrm{plant}^{-1}\right]$} & \multicolumn{3}{|c|}{ Element concentration $\left[\mathrm{g} \mathrm{kg} \mathrm{DW}^{-1}\right]$} & \multirow{2}{*}{ Colonization* $[\%]$} \\
\hline & Root & Shoot & $\mathrm{N}$ & $\mathrm{P}$ & $\mathrm{K}$ & \\
\hline AM1-OSM- & 0.24 & 1.05 & 10.75 & 2.20 & 3.12 & 0 \\
\hline AM1+OSM- & 0.37 & 1.45 & 14.00 & 3.17 & 4.40 & $9.00 \pm 3.50$ \\
\hline AM1-OSM+ & 0.43 & 1.63 & 14.25 & 3.42 & 3.42 & 0 \\
\hline $\mathrm{AM} 1+\mathrm{OSM}+$ & 0.56 & 2.28 & 18.00 & 3.30 & 4.57 & $8.25 \pm 2.50$ \\
\hline Effects of AM1 & $p<0.001$ & $p<0.001$ & $p<0.001$ & $p<0.001$ & $p<0.001$ & - \\
\hline Effects of OSM & $p<0.001$ & $p<0.001$ & $p<0.001$ & ns & ns & - \\
\hline $\begin{array}{l}\text { Effects of AM1 } \mathrm{x} \\
\text { OSM }\end{array}$ & ns & ns & ns & ns & ns & - \\
\hline
\end{tabular}

Rooted pelargonium cuttings were grown in substrate complemented with Osmocote (OSM+) or without Osmocote (OSM-) and inoculated with Symbivit (AM1+) or left without inoculation (AM1-).

Each data represents a mean value of five replicates. Effects of the treatments [mycorrhizal inoculation (AM1); nutrient supply in the form of Osmocote(OSM)] were tested with a two-way ANOVA.

Mycorrhizal inoculation increased the weight of shoots and roots alike irrespectively of their nutrient supply but there was no significant interaction between OSM and AM1 treatments with regard to the mass of roots and shoots. Inoculation with Symbivit enhanced the N, K and P concentrations in the shoots of pelargonium plants in both treatments (OSM+, OSM-). Osmocote supply increased the growth of pelargonium, but only had a significant effect on the increase in nitrogen concentrations of all the elements tested. 


\section{AGRICULTURAL AND FOOD SCIENCE}

G. Csima et al. (2012) 21: 52-61

There were no significant differences in the number of colony forming units (CFUs) of microorganisms (fungi, bacteria and Pseudomonas groups) between the different treatments after six weeks growth (Fig. 1).

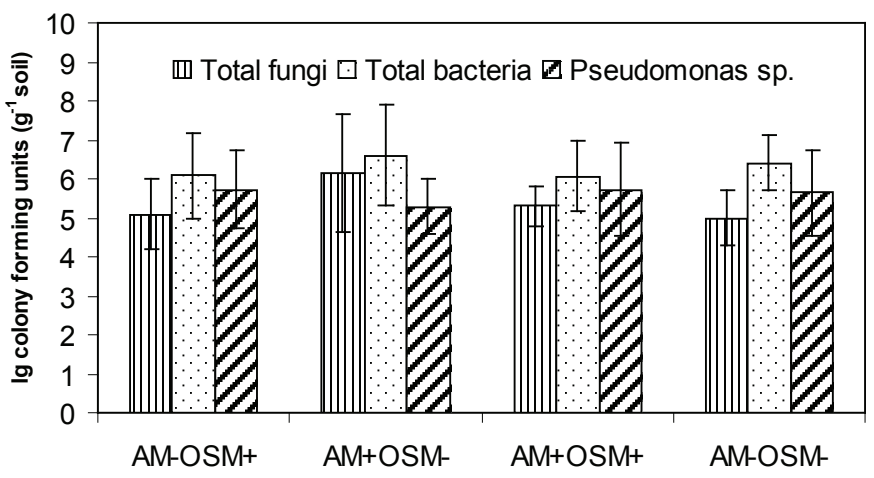

\section{Experiment 2. Inoculation with mycorrhizal fungi during transplantation}

Post-transplant inoculation with Symbivit increased mycorrhizal colonization irrespective of inoculation prior to transplantation or nutrient supply (Table 2). The inoculation of non-mycorrhizal plants growing in nutrient deficient substrate showed the same colonization level as the post-inoculation of mycorrhizal plants in OSM- or OSM+ treatments.

Post-transplant inoculation decreased shoot growth in plants without initial OSM treatment regardless of whether they received pre-AM inoculation or not (Table 2). However, post-transplant inoculation with initial OSM treatment had no significant effect on shoot mass either with (AM1+) or without (AM1-) preinoculation. The carry-over effect showed different tendencies. In OSM+ treatments the carry-over effect resulted in significant increase in shoot growth. While the shoot mass of pre-inoculated plants (AM1+) increased significantly as a result of post-AM inoculation compared to figures obtained in OSM+ conditions, in nutrient deficient conditions (OSM-) with AM2+ inoculation significant decrease in shoot mass was observed compared to the shoot mass of plants without initial inoculation.

There was no significant difference in the root dry weight due to post-transplant mycorrhizal inoculation, based on the results of the same OSM and AM1 treatments. Additional AM inoculation (AM2+) applied to pre-inoculated plants without Osmocote caused significant decrease in root mass in relation to AM1-OSMtreatments. However, in OSM+ conditions with $\mathrm{AM} 1+$ treatment, post-inoculation resulted in significant increase in root mass compared to AM1- plants.

Potassium concentrations in shoots were not influenced by post-transplant inoculation, but in OSM- conditions potassium concentration of pre-inoculated plants increased significantly as a result of additional inoculation. Post-transplant inoculation enhanced nitrogen concentrations in shoots in all treatments. 


\section{AGRICULTURAL AND FOOD SCIENCE}

G. Csima et al. (2012) 21: 52-61

Phosphorus concentrations in shoots were increased by post-transplant inoculation in AM1-OSM- plants and decreased in $\mathrm{AM} 1+\mathrm{OSM}+$ plants. As a result of additional inoculation in OSM+ conditions the phosphorous concentration of pre-inoculated plants increased compared to AM1-OSM+AM2+ plants.

Table 2. Effects of mycorrhizal inoculation and nutrient supply on growth, element concentrations measured in shoots and root colonization after 12 weeks of growth.

\begin{tabular}{|c|c|c|c|c|c|c|}
\hline \multirow{2}{*}{ Treatments } & \multicolumn{2}{|c|}{ Dry weight [g plant $\left.{ }^{-1}\right]$} & \multicolumn{3}{|c|}{ Element concentration $\left[\mathrm{g} \mathrm{kg} \mathrm{DW}^{-1}\right]$} & \multirow{2}{*}{ Colonization* $[\%]$} \\
\hline & Root & Shoot & $\mathrm{N}$ & $\mathrm{P}$ & $\mathrm{K}$ & \\
\hline AM1-OSM- & $1.00 \mathrm{~b}$ & $1.40 \mathrm{~b}$ & $10.25 \mathrm{a}$ & $1.70 \mathrm{a}$ & $4.27 \mathrm{a}$ & 0 \\
\hline AM1-OSM-AM2+ & $1.05 \mathrm{~b}$ & $1.24 \mathrm{a}$ & $14.25 \mathrm{~b}$ & $2.22 \mathrm{~b}$ & $4.25 \mathrm{a}$ & $55.50 \pm 9.50$ \\
\hline AM1+OSM- & $0.72 \mathrm{a}$ & $1.83 \mathrm{~b}$ & $13.25 \mathrm{~b}$ & $2.07 \mathrm{~b}$ & $5.02 \mathrm{~b}$ & $35.25 \pm 5.50$ \\
\hline AM1+OSM-AM2+ & $0.75 \mathrm{a}$ & $0.98 \mathrm{a}$ & $16.25 \mathrm{c}$ & $2.27 \mathrm{~b}$ & $4.42 \mathrm{~b}$ & $52.25 \pm 8.25$ \\
\hline AM1-OSM+ & $2.27 \mathrm{c}$ & $3.55 \mathrm{c}$ & $14.75 \mathrm{bc}$ & $2.85 \mathrm{c}$ & $5.37 \mathrm{~b}$ & 0 \\
\hline $\mathrm{AM} 1-\mathrm{OSM}+\mathrm{AM} 2+$ & $1.82 \mathrm{c}$ & $3.22 \mathrm{c}$ & $15.75 \mathrm{c}$ & $3.05 \mathrm{c}$ & $4.85 \mathrm{~b}$ & $34.25 \pm 5.00$ \\
\hline $\mathrm{AM} 1+\mathrm{OSM}+$ & $2.66 \mathrm{~d}$ & $4.28 \mathrm{~d}$ & $12.25 \mathrm{~b}$ & $4.52 \mathrm{e}$ & $4.90 \mathrm{~b}$ & $46.75 \pm 4.25$ \\
\hline $\mathrm{AM} 1+\mathrm{OSM}+\mathrm{AM} 2+$ & $2.62 \mathrm{~d}$ & $3.89 \mathrm{~d}$ & $18.50 \mathrm{~d}$ & $3.22 \mathrm{~d}$ & $4.62 \mathrm{~b}$ & $55.00 \pm 9.00$ \\
\hline
\end{tabular}

Rooted pelargonium cuttings were grown in substrate complemented with Osmocote (OSM+) or without Osmocote (OSM-) and inoculated with Symbivit (AM1+) or left without inoculation (AM1-). Inoculation with Symbivit during transplanting is indicated as AM2+. Each data represents a mean value of five replicates. Different letters denote significant differences between means within one factor determined by the Tukey test $(p<0.05)$.

$*$ The data are the means of five replicates \pm standard error.

\section{Molecular analysis}

The primer pair used in this study, $27 \mathrm{f}$ and $534 \mathrm{r}$, amplified PCR products with the expected sizes of approximately 500 - 550 basis pairs (Fig. 2), which after being digested by two restriction enzymes and run on agarose gel, a band of $300 \mathrm{bp}$ in size appeared in all treatments. There were at least four additional bands observed in smaller size range. As a result of pre-inoculation (AM1+) in OSM- treatments the agarose gel pattern of DNA (amplified with $27 \mathrm{f}$ and $534 \mathrm{r}$ primers and digested with two restriction enzymes) originating from bacterial community of the rizosphere showed differences in the sixth week. New bands of approximately $200 \mathrm{bp}$ in size appeared not only in here but also in samples of experiment 2, but only when both the OSM-conditions and the pre-or post-mycorrhizal inoculation were present simultaneously. 


\section{AGRICULTURAL AND FOOD SCIENCE}

G. Csima et al. (2012) 21: 52-61

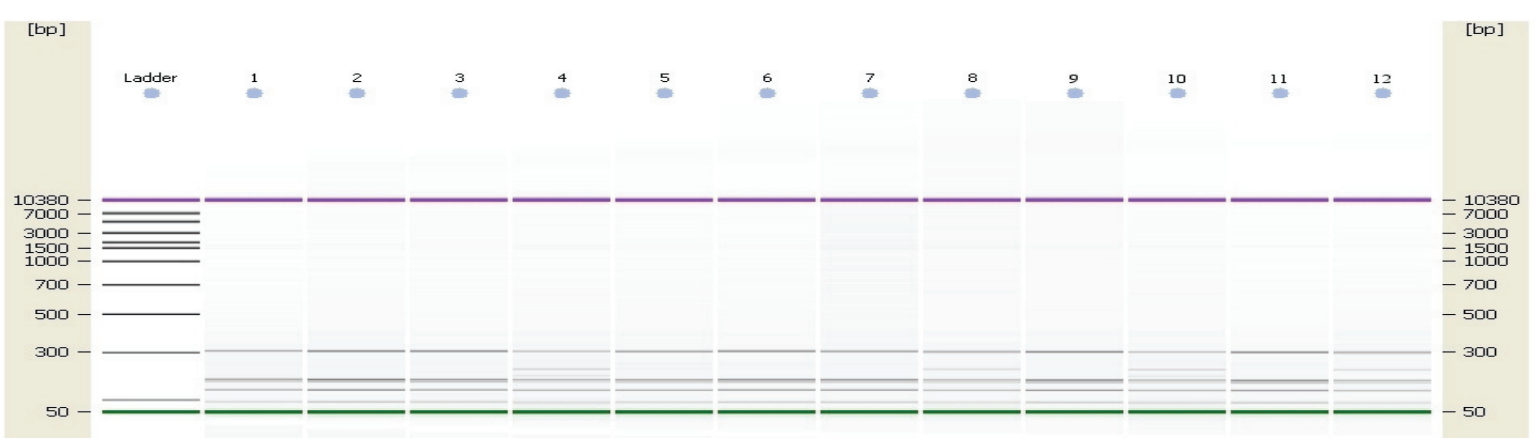

Fig. 2. Effects of mycorrhizal inoculation and nutrient supply on RFLP profiles of amplified fragment with primer pairs of $27 \mathrm{f}$ and $534 \mathrm{r}$ after digestion with endonucleases Hin6I (HinP1I) and BsuRI (HaeIII)

L: Ladder, Line 1-4 regarding after six weeks of growth: 1: AM1-OSM+; 2: AM1-OSM-; 3: AM1+OSM+; 4: AM1+OSM-; Line 5-12 regarding after 12 weeks of growth: 5: AM1-OSM+; 6: AM1-OSM-; 7: AM1+OSM+; 8: AM1+OSM-; 9: AM1OSM+AM2+; 10: AM1+OSM-AM2+; 11: AM1+OSM+AM2+; 12: AM1-OSM-AM2+

Rooted pelargonium cuttings were grown in substrate complemented with Osmocote (OSM + ) or without Osmocote (OSM-) and inoculated with Symbivit (AM1+) or left without inoculation (AM1-). Treatments showing inoculation with Symbivit during transplanting are nominated after Osmocote label (AM1-OSM+AM2+, AM1-OSM-AM2+, AM1+OSM$\mathrm{AM} 2+, \mathrm{AM} 1+\mathrm{OSM}+\mathrm{AM} 2+)$.

\section{Discussion}

Pelargonium is one of the most important ornamental plants in Hungary, and there is an increasing need for microbiological methods which could assist in the production of high quality, marketable plants. One such beneficial method is mycorrhizal inoculation, which has the advantage of stimulating earlier growth and increasing the size of flowers while decreasing the nutrient and irrigation water requirement of plants. Although there have been sporadic publications in mycorrhizal inoculation of pelargonium (Nowak 2004, Perner et al. 2007), little information is still available with regard to pre-and post-transplant mycorrhizal inoculation. In large scale production horticultural substrates are usually supplemented with nutrients that could depress mycorrhizal colonization. Our results confirm those of Williams et al. (1992) as well as the findings of Linderman and Davies (2004), according to which AMF cooperate well with controlled phosphorous-supplying fertilizers used in our experiments.

Although only less than $10 \%$ colonization level could be detected in week 6 following inoculation, the effect of mycorrhizal inoculation on increasing shoot growth and NPK concentrations of plants could be demonstrated. These data regarding root colonization are in contrast to the results of Biermann and Lindermann (1983) who measured higher colonization levels both at low (11 ppm P) and higher (43 ppm P) phosphorus concentrations in the substrate, $53 \%$ and $22 \%$ respectively. However, they applied a different method from ours in which pre-germinated pelargonium seedlings as young as two days old were inoculated and fertilized with monobasic sodium phosphate.

Mycorrhizal fungi are well known for their efficient phosphorous uptake, but the contribution of AMF to the potassium and nitrogen supply of plants has been less frequently studied (Venkateshwar Rao et al. 2002, Zerche et al. 2008). Our results showed that mycorrhizal inoculation, especially the carry-over effect of AM inoculation increased nitrogen uptake. The influence of arbuscular mycorrhizal fungi on nitrogen uptake is poorly understood, only a few studies showed that arbuscular mycorrhizal roots can accelerate the decomposition of organic nitrogen (Hodge et al. 2001, Talbot and Treseder 2010) and only some provide evidence that AMF contribute to organic nitrogen decomposition (Hodge et al. 2001). Interestingly 


\section{AGRICULTURAL AND FOOD SCIENCE}

G. Csima et al. (2012) 21: 52-61

the carry over effect of AM inoculation increased the P-uptake only in OSM+ and K-uptake in nutrient deficient (OSM-) conditions.

Based on our results of the sixth week of growing we decided to investigate the differences in the bacterial communities of the rhizosphere between the inoculated and non-inoculated plants, since there is a lot of experimental evidence pointing to the essential role beneficial microorganism play in the uptake of mineral elements of plants. Although, CFUs of total fungi and bacteria in the rhizosphere were not influenced by AMF, the RFLP profiles using only two restriction enzymes showed more diverse bacterial population of mycorrhizal plants treated without OSM (OSM-) than in other treatments. By means of RFLP profiling we were not able to identify the species present, but the changes in the diversity of bacterial community could be observed due to mycorrhizal inoculation at low nutrient supply. Interestingly, the same tendencies could be observed in the results of the second experiment.

Under nutrient deficient conditions similar changes could be observed in the composition of bacterial community of the rhizosphere due to mycorrhizal inoculation irrespective of whether the plants received $\mathrm{AM} 1+$ (pre transplantation) or AM2+(post transplantation) treatments.

The effect of AMF on microorganisms could be monitored not only in the rhizosphere but also in hyphosphere (Posta et al. 1994) or mycosphere as described by Linderman (1988). On the other hand, some reports showed that PGPR (plant growth promotion rhizobacteria), involved in nutrient cycling, have a strong stimulatory impact on the growth of AM fungi (Andrade et al. 1997) and vice versa, AMF could increase the concentration of some microorganisms (Meyer and Lindermann 1986).

Furthermore, the occurrence of bacteria and fungi species may depend upon root exudations and/or other factors under phosphorous stress. Root exudates are crucial determinants of rhizosphere microorganism diversity as shown by Marschner (1998). Plants grown in soils with phosphorous deficiency can exudate functional substances, such as organic acids, jasmonic acid, phosphatases and phenolic compounds which can stimulate colonization and growth of the mycorrhizal fungi (Marschner 1998, Hinsinger 2001, Koide and Mosse 2004). Many rhizobacteria, for example phosphate solubilizing bacteria (PSB) and fungi are able to solubilize sparingly soluble phosphates, usually by releasing chelating organic acids (Kucey et al. 1989, Richardson 2001, Vessey 2003) and/or producing phosphatases for mobilization of organic phosphorous which influence the nutrient uptake of plants.

In conclusion, it can be stated that inoculation with Symbivit containing mycorrhizal fungi could be an integral part of pelargonium production. Pre-inoculation may be the most practical way to establish AMF on container-grown plants since less inoculum is required and resulted in larger plants at higher nutrient level than post-transplant inoculation. Mycorrhizal inoculation resulted in changes in the rhizosphere mostly in substrates low in nutrients and the interactions between AMF and rhizobacteria could make a biotechnological tool essential for boosting plant growth in horticultural practices in the future.

\section{Acknowledgments}

The authors thank Andrea Gógán Csorbainé for technical help and comments on pilot experiment. Research was supported/subsidized by the TÁMOP-4.2.2.B-10/1 „Development of a complex educational assistance/ support system for talented students and prospective researchers at the Szent István University" project and by Eurostars Project Microfruit E!4366. Authors are grateful to EC COST 870 program. 


\section{AGRICULTURAL AND FOOD SCIENCE}

G. Csima et al. (2012) 21: 52-61

\section{References}

Andrade, G., Mihara, K.L., Linderman, R.G. \& Bethlenfalvay, G.J. 1997. Bacteria from rhizosphere and hyphosphere soils of different arbuscular-mycorrhizal fungi. Plant and Soil 192: 71-79.

Azcón-Aguilar, C. \& Barea, J.M. 1997. Applying mycorrhiza biotechnology to horticulture: significance and potentials. Scientia Horticulturae 68: 1-24.

Benton, J.J. 1991. Kjeldahl Method for Nitrogen Determination. Micro-Macro Publishing, Athens. p. 1-9.

Biermann, B. \& Linderman, R.G. 1983. Increased geranium growth using pretransplant inoculation with a mycorrhizal fungus. Journal of the American Society for Horticultural Science 108(6): 972-976.

Egner, H., Riehm, H. \& Mingo, W.R. 1960. Untersuchungen über die chemische Bodenanalyse als Grundlage für die Beurteilung des Nährstoffzustandes der Böden. Kungl Lantbrukshögsk Ann Uppsala 26: 199-215.

George, E. 2000. Nutrient uptake. Contribution of arbuscular mycorrhizal fungi to plant mineral nutrition. In: Kapulnik Y. \& Douds D.D. Jr. (eds.). Arbuscular mycorrhizas: physiology and function. Kluwer Academic Publishers, Netherlands. p. 307-343.

Giovanetti, M. \& Mosse, B. 1980. An evaluation of techniques for measuring vesicular-arbuscular mycorrhizal infection in roots. New Phytologist 84: 489-500.

Hinsinger, P. 2001. Bioavailability of soil inorganic P in the rhizosphere as affected by root-induced chemical changes: a review. Plant and Soil 237: 173-195.

Hodge, A., Campbell, C.D. \& Fitter, A.H. 2001. An arbuscular mycorrhizal fungus accelerates decomposition and acquires nitrogen directly from organic material. Nature 413: 297-299.

Koide, R.T. \& Mosse, B. 2004. A history of research on arbuscular mycorrhiza. Mycorrhiza 14: 145-163.

Kucey, R.M.N. \& Leggett, M.E. 1989. Increased yields and phosphorus uptake by Westar canola (Brassica napus L.) inoculated with phosphate solubilizing isolate of Penicillium bilaji. Canadian Journal of Soil Science 69: 425-432.

Linderman, R.G. 1988. Mycorrhizal interactions with the rhizosphere microflora: The mycorrhizosphere effect. Phytopathology 78: 366-371.

Linderman, R.G. \& Davis, E.A. 2004. Varied response of marigold (Tagetes spp.) genotypes to inoculation with different arbuscular mycorrhizal fungi. Scientia Horticulturae 99: 67-78.

Lovato, P.E., Schüepp, A., Truvelot, A. \& Gianazzi, S. 1995. Application of arbuscular mycorrhizal fungi (AMF) in orchard and ornamental plants. In: Varma, A. \& Hock, B. (eds.). Mycorrhiza Structure, Function, Molecular Biology and Biotechnology. Springer, Heidelberg. p. 521-559.

Marschner, H. 1998. Role of root growth, arbuscular mycorrhiza, and root exudates for the efficiency in nutrient acquisition. Field Crops Research 56: 203-207.

Menge, J.A., Lembright, H. \& Johnson, E.L.V. 1977. Utilization of mycorrhizal fungi in citrus nurseries. Proceedings of the International Society of Citriculture 1: 129-132.

Meyer, J.R. \& Linderman, R.G. 1986. Selective influence on populations of rhizosphere or rhizoplane bacteria and actinomycetes by mycorrhizas formed by Glomus fasciculatum. Soil Biology and Biochemistry 18: 191-196.

Muyzer, G., de Waal, E. \& Uitierlinden, G. 1993. Profiling of Complex Microbial Populations by Denaturing Gradient Gel Electrophoresis Analysis of Polymerase Chain Reaction-Amplified Genes Coding for 16S rRNA. Applied and Environmental Microbiology 3: 695-700.

Nagahashi, G., Douds, Jr., D.D. \& Abney, G.D. 1995. Phosphorus amendment inhibits hyphal branching of the VAM fungus Gigaspora margarita directly and indirectly through its effect on root exudation. Mycorrhiza 6: 403-408.

Nowak, J. 2004. Effects of arbuscular mycorrhizal fungi and organic fertilization on growth, flowering, nutrient uptake, photosynthesis and transpiration of geranium (Pelargonium hortorum L.H. Bailey'Tango Orange'). Symbiosis 37: $259-266$.

Nowak, J. 2007. Effects of lead concentration and arbuscular mycorrhiza on growth, flowering and lead accumulation in shoots of Pelargonium hortorum L.H. Bailey 'Tango Orange'. Roczniki Akademii Rolnicej w Poznaniu CCCLXXXIII, Ogrodn 41: 147-151.

Perner, H., Schwarz, D., Bruns, C., Mäder, P. \& George, E. 2007. Effect of arbuscular mycorrhizal colonization and two levels of compost supply on nutrient uptake and flowering of pelargonium plants. Mycorrhiza 17: 469-474. 


\section{AGRICULTURAL AND FOOD SCIENCE}

G. Csima et al. (2012) 21: 52-61

Phillips, J.M. \& Hayman, D.S. 1970. Improved procedures for clearing roots and staining parasitic and vesicular-arbuscular mycorrhizal fungi for rapid assessment of infection. Transactions of the British Mycological Society 55: $158-161$.

Posta, K., Marschner, H. \& Römheld, V. 1994. Manganese reduction in the rhizosphere of mycorrhizal and non mycorrhizal maize. Mycorrhiza 5: 119-124.

Richardson, A.E. 2001. Prospects for using soil microorganisms to improve the acquisition of phophorus by plants. Australian Journal of Plant Physiology 28: 897-906.

Schützendübel, A. \& Polle, A. 2002. Plant responses to abiotic stresses: heavy metal-induced oxidative stress and protection by mycorrhization. Journal of experimental botany 53: 1351-1365.

Talbot, J.M. \& Treseder, K.K. 2010. Controls over mycorrhizal uptake of organic nitrogen. Pedobiologia 53: 169-179.

Venkateshwar Rao, G., Manoharachary, C. \& Rajeswara Rao, B. 2002. Beneficial influence of arbuscular mycorrhizal fungal association on growth, yield and nutrient uptake of rose-scented geranium (Pelargonium species). Philippine Journal of Science 131: 49-58.

Vessey, J.K. 2003. Plant growth promoting rhizobacteria as biofertilizers. Plant and Soil 255: 571-586.

Williams, S.C.K., Vestberg, M., Uosukainen, M., Dodd, J.C. \& Jeffries, P. 1992. Effects of fertilizers and arbuscular mycorrhizal fungi on the post-vitro growth of micropropagated strawberry. Agronomie 12: 851-857.

Zerche, S., Druege, U. \& Kadner, R. 2008. Nitrogen absorption, growth of stock plants, and adventious rooting of Pelargonium $x$ hortorum cuttings as affected by the form and dosage of nitrogen. Journal of Horticultural Science and Biotechnology 83: 207-217. 